\title{
SERVIÇO SOCIAL E O CUIDADO EM SAÚDE ${ }^{1}$
}

\author{
SOCIAL WORK AND HEALTH CARE
}

Alaide Maria Morita Fernandes da Silva ${ }^{2}$

Maria Lucia Rodrigues ${ }^{3}$

\section{RESUMO}

Este artigo tem como objetivo refletir sobre a relação do serviço social com o cuidado em saúde tendo como pressuposto que sua atuação se vincula aos eixos teórico-práticos da política de saúde do SUS/Sistema Único de Saúde. A reflexão articula o trabalho do assistente social com o cuidado em saúde na perspectiva de elevar a qualidade do serviço prestado, assim como seu papel mediador diante dos fatores que produzem sofrimentos aos usuários.

PALAVRAS-CHAVE: Cuidado em saúde. Serviço Social. Trabalho.

\begin{abstract}
This article aims to reflect on the relationship of social work with health care from the assumption that its performance is linked to theoretical and practical axes of health policy in the context of SUS. It is emphasized that the way he understands and faces a problem is connected to a principle of humanization that comes to care for and raise the human species. Reflection allows establishing social service connections to health care identifying the caring dimension of work social worker, as well as its mediating role on the factors that produce suffering to users of health services, considering them partakers in the process.
\end{abstract}

KEYWORDS: Health Care. Social Work. Health Work.

\section{INTRODUÇÃO}

Este artigo parte do pressuposto de que o Serviço Social está intrinsecamente relacionado ao cuidado em saúde. Enquanto um dos gestores do cuidado na equipe de trabalho, o assistente social tem possibilidade de articular dimensões da vida dos

\footnotetext{
${ }^{1} \mathrm{O}$ texto é inédito e a pesquisa foi aprovada pelo Comitê de Ética em Pesquisa da Pontifícia Universidade Católica de São Paulo sob Parecer PF No 24939, em 21/05/2012.

${ }^{2}$ Doutora em Serviço Social e Professora do Curso de Serviço Social do Centro de Estudos Sociais Aplicados/ Universidade Estadual de Londrina. E-mail keikomorita902@gmail.com. Telefone 5543 99150089.

${ }^{3}$ Doutora em Serviço Social, Professora Titular do Programa de Estudos Pós-Graduados em Serviço Social da PUC/SP, Coordenadora do Núcleo de Estudos e Pesquisas sobre Complexidade, Ensino e Questões Metodológicas em Serviço Social da PUC/SP. E-mail nemess@pucsp.br. Telefone 551136708512.
} 
usuários que nem sempre são valorizadas ou possíveis de serem incorporadas por outros profissionais no ato de cuidar, mas que podem ser imprescindíveis para viabilizá-lo.

Apesar de ser uma finalidade do trabalho nesta área, o cuidado não se constitui um objeto de discussão no Serviço Social e apresenta-se como uma "questão nova" cujos conhecimentos precisam ser construídos. Mas, qual seria a relação entre o Serviço Social e o cuidado em saúde?

Neste texto discorremos sobre esta relação com o objetivo de ampliar a discussão para além da área da saúde, com o propósito de aprofundar a compreensão desta atividade no campo de trabalho realizado pelo Serviço Social. O estudo resulta de uma pesquisa que resultou na tese de doutorado que tem por título "Produção do cuidado em saúde e o Serviço Social" 4.

Mas de qual cuidado estamos falando? Existe um conceito de cuidado em saúde? Qual é o entendimento de cuidado em saúde para o assistente social esta atividade pode ser identificada em seu trabalho? Para responder estas questões, extraímos dos dados empíricos obtidos nos grupos de discussão realizados com assistentes sociais sujeitos da pesquisa, concepções relativas ao cuidado em saúde e suas múltiplas expressões na prática desses profissionais.

Para compreender a atuação do assistente social na perspectiva do cuidado em saúde é necessário considerar que as ações no âmbito individual e coletivo requerem conhecimentos e a aquisição de conceitos que podem ressignificar a prática profissional. Quais conceitos podem contribuir para isto?

Recorremos às formulações de diferentes autores do Serviço Social e da Saúde Coletiva, principalmente aqueles que focalizam a dimensão micropolítica do trabalho, de conceitos-ferramentas, como por exemplo: cuidado, tecnologia, linhas de cuidado, $e$ outros, pois são eles que contribuem para a apreensão e ressignificação dos processos relacionais da produção do cuidado, onde quer que eles ocorram. Esclarecemos que o estudo foi realizado no município de Londrina tendo como foco a Residência Multiprofissional em Saúde da Família e o Serviço Social na saúde. O universo compreendeu profissionais de saúde inseridos no curso e na rede pública de serviços de saúde 5 .

\footnotetext{
${ }^{4}$ Tese defendida em 2013 na Pontifícia Universidade Católica de São Paulo-PUC/SP por Alaide Maria Morita Fernandes da Silva sob a orientação da Dra. Maria Lucia Rodrigues.

${ }^{5}$ A rede de pública de serviços de saúde é constituída por níveis de atenção denominada por básica, secundária e terciária e os assistentes sociais estão alocados nos três níveis.
}

Serv. Soc. \& Saúde, Campinas, SP v. 14, n. 1 (19), p. 39-56, jan./jun. 2015 ISSN 1676-6806 
$\mathrm{O}$ artigo divide-se em duas partes: a primeira se refere à dimensão cuidadora do trabalho do assistente social no contexto das diretrizes do Sistema Único de Saúde (SUS) e, a segunda, discorre sobre o assistente social na gestão do cuidado em saúde, destacando suas ações profissionais no cuidado individual, familiar e na equipe de trabalho.

\section{A dimensão cuidadora do trabalho do assistente social}

Embora um dos maiores espaços de atuação do assistente social ao longo de sua história tenha sido a área da saúde, principalmente no campo hospitalar, a necessidade de construir um novo modelo de atenção à saúde baseado numa concepção ampliada e nos determinantes sociais ${ }^{6}$ do processo saúde-doença, trouxe novas perspectivas e desafios para o seu trabalho.

Hoje, o Serviço Social é reconhecido como um profissional de saúde e está sendo convidado a compor equipes multiprofissionais no campo da saúde cujo objetivo prioritário consiste em produzir o cuidado; mas, qual é a relação da profissão nessa produção?

Primeiramente é preciso esclarecer que o sentido de cuidado que estamos utilizando é aquele que supera a dimensão biológica e, ao contrário de sua interpretação reduzida e biologicizada, tem um sentido mais abrangente. A difusão do paradigma da produção social da saúde como um processo que envolve múltiplos aspectos objetivos e subjetivos passou a ser reconhecido como matéria de intervenção multiprofissional e, isto, transformou o cuidado em objeto de diferentes profissões.

Profundamente articulado aos princípios do Sistema Único de Saúde - SUS, o cuidado em saúde nos remete a questões filosóficas do "ser" humano nas relações sociais e isto vem ao encontro dos principais pressupostos teórico-metodológicos do Serviço Social em sua formação e exercício profissional.

Esse direcionamento do trabalho está vinculado a uma noção de cuidado que diz respeito ao modo como os profissionais articulam seus conhecimentos e saberes em benefício dos usuários, ou seja, a uma postura e atitude de respeito às diferenças na perspectiva de um cuidado humanizado.

\footnotetext{
6 "A saúde tem como fatores determinantes e condicionantes, entre outros, a alimentação, a moradia, o saneamento básico, o meio ambiente, o trabalho, a renda, a educação, o transporte, o lazer e o acesso aos bens e serviços essenciais; os níveis de saúde da população expressam a organização social e econômica do País" (BRASIL, 1990. Art. $\left.3^{\circ}\right)$.
} 
O cuidado humanizado é, conforme observa Deslandes, mais que um valor pois que se refere a um ethos e diz respeito a "[...] uma ética definidora de práticas e identidades", ou seja,

[...] 1) uma postura/atitude em relação ao outro, em relação a si mesmo como cuidador e a própria relação terapêutica; 2) mobiliza um certo nível de conhecimentos disponíveis, além de 3) envolver um conjunto de disposições organizacionais relacionadas às condições de produção desse cuidado (DESLANDES, 2007, p. 392).

As dimensões apontadas pela autora reforçam os eixos de análise que vêm sendo explorados no campo da Saúde Coletiva e que transitam no campo filosófico, político, das tecnologias de trabalho e das condições institucionais da produção do cuidado.

Segundo Merhy (2002), o trabalho em saúde faz uso de ferramentas tecnológicas, denominadas de leves, leve-duras e duras ${ }^{7}$ e o cuidado, que é essencialmente relacional, dependeria do modo como cada trabalhador articula tais ferramentas. Com base nas formulações deste autor é possível dizer que o trabalho do assistente social se caracteriza pelo predomínio de tecnologia leves, ou seja, das relações.

Tendo a questão social como base de sua fundamentação, o assistente social se insere em processos de trabalho em que o cuidado à saúde requer conhecimentos sobre um contexto interligado em que vivem seus usuários, que incluem os determinantes sociais, econômicos, culturais, religiosos, ambientais, suas relações familiares e o meio onde vive etc, denominadas como condições de vida.

A intervenção do assistente social é uma dimensão da prática profissional objetivada pela sua intencionalidade de transformação social que dá às ações, em seus aspectos objetivos e subjetivos, originalidade e uma forma específica de abordar os problemas na realidade social.

As demandas que chegam ao Serviço Social nos serviços de saúde estão relacionadas à questões que ampliam a vulnerabilidade de distintos segmentos da população em sua situação de saúde, tais como: precariedade e/ou à ausência de moradia, violência urbana e doméstica, situações de negligência e abandono, acidentes

\footnotetext{
${ }^{7}$ A expressão tecnologia é utilizada por Merhy, para se referir às ferramentas e às dimensões que envolvem o processo de produção do cuidado, classificando-as em: [...] leves (como no caso das tecnologias de relações do tipo produção de vínculo, autonomização, acolhimento, gestão como uma forma de governar processos de trabalho), leveduras (como no caso de saberes bem estruturados que operam no processo de trabalho em saúde, como a clínica médica, a clínica psicanalítica, a epidemiologia, o taylorismo, o fayolismo) e duras (como no caso de equipamentos do tipo máquinas, normas, estruturas organizacionais) (MERHY, 2002, p. 49).
} 
de trabalho, desemprego, dificuldade de acesso à consultas com especialistas e medicamentos, etc.

Ainda que o assistente social seja um profissional que se proponha garantir os direitos constitucionais cujas leis, muitas vezes, não encontram ressonância na realidade e/ou não têm condições de serem aplicadas, isto não deve ser interpretado como um obstáculo, mas como um desafio e como um campo de atuação profissional aberto para ações cuidadoras, no sentido proposto pela própria política de saúde. Nem todos os problemas de saúde podem ser curados, mas podem ser cuidados para diminuir o sofrimento e/ou o próprio impacto da doença, compartilhando com os usuários e seus familiares a construção de alternativas para o enfrentamento de seus problemas. Segundo Castro e Castro, a incorporação dessa dimensão cuidadora ao trabalho do assistente social consiste em

[...] optar por uma abordagem ampliada e qualificada do problema de saúde e de suas determinações, a partir do cotidiano dos usuários, é possibilitar a abertura de canais de escuta e comunicação propiciando a democratização das informações, a efetivação da educação em saúde e dos princípios do SUS, e a busca pelo fim da supremacia de uma profissão sobre a outra (CASTRO e CASTRO, 2007, p. 145),

Faz emergir, especialmente, a natureza multiprofissional do trabalho em saúde e a constituição de um campo comum a todos os profissionais. A complexa realidade que se apresenta como demanda aos serviços de saúde demonstra que

[...] assim como a questão do sofrimento não deve se restringir à área sanitária, tendo em vista que muitos de seus determinantes estão diretamente relacionados à conjuntura socioeconômica e política, a discussão da integralidade na atenção e no cuidado desses sujeitos também implica uma abordagem interdisciplinar (LACERDA; VALLA, 2005, p. 92).

Enquanto operador do cuidado, o assistente social busca ampliar a autonomia dos sujeitos diante dos fatores que produzem sofrimentos, considerando-os coparticipantes nesse processo. Suas ações no âmbito individual e coletivo se direcionam para a identificação das necessidades sociais de saúde da população, buscando viabilizar direitos de cidadania e o fortalecimento do protagonismo dos sujeitos no processo saúde-doença.

O assistente social na saúde trabalha na defesa dos direitos dos seus usuários tanto individual quanto coletiva, ouvindo e buscando atender necessidades e superar as dificuldades institucionais e de saúde. Vários estudos indicam as habilidades da profissão nessa direção; é possível afirmar que a valorização profissional está vinculada Serv. Soc. \& Saúde, Campinas, SP v.14, n.1(19), p. 39-56, jan./jun. 2015 ISSN 1676-6806 
à capacidade de percorrer caminhos dentro e fora da instituição em que trabalha, contribuindo para viabilizar o atendimento na direção da promoção da saúde do ponto de vista da política de saúde como a integralidade da atenção, as necessidades sociais de saúde $^{8}$ e a construção de linhas de cuidado ${ }^{9}$.

As linhas de cuidado podem ser acionadas a partir de Projetos Terapêuticos ${ }^{10}$ Singulares (PTS), cujo sentido não se reduz ao conceito de terapia utilizado no sentido biomédico de tratamento de enfermidades, mas de uma construção coletiva com a participação de trabalhadores e usuários conforme as necessidades identificadas pela equipe. As linhas de cuidado também são pensadas, segundo Silva e Magalhães Junior (2008), como estratégias utilizadas em determinadas situações tais como nas doenças crônicas, por exemplo, para orientar os usuários ao que devem fazer na rede conforme suas necessidades.

Dessa forma, o processo de gestão do cuidado em saúde é um campo onde vários sujeitos podem atuar nas múltiplas dimensões em que ele (o cuidado) se fizer necessário. Ou seja, na perspectiva da integralidade da saúde, a família, os trabalhadores da saúde, os serviços de saúde e/ou outros setores podem ser acionados (ou deveriam), para formar uma rede de cuidados para atender necessidades específicas de cada usuário.

\section{O assistente social na gestão do cuidado em saúde}

O termo gestão está vinculado à ideia de gerir, governar a produção, mas na saúde se diferencia da administração, do conceito gerencial. Para Barros e Barros, 2007, p.81, “[...] a gestão não é mais identificada apenas a um cargo ou um lugar (o lugar do

\footnotetext{
${ }^{8}$ As necessidades de saúde não se restringem à ausência de doenças e dizem respeito aos fatores determinantes de saúde, podendo ser agrupadas em quatro conjuntos: ter "boas condições de vida"; ter acesso e poder consumir toda tecnologia capaz de melhorar e prolongar a vida; criação de vínculos

(a)efetivos entre cada usuário e uma equipe e/ou um profissional (encontro de subjetividades); ter graus crescentes de autonomia no seu modo de andar a vida (CECÍLIO, 2001).

${ }^{9}$ Segundo Franco e Franco (s/d), "linha do cuidado é uma imagem pensada para expressar os fluxos assistenciais seguros e garantidos ao usuário, no sentido de atender às suas necessidades de saúde. É como se ela desenhasse o itinerário que o usuário faz por dentro de uma rede de saúde incluindo segmentos não necessariamente inseridos no sistema de saúde, mas que participam de alguma forma da rede, tal como entidades comunitárias e de assistência social”.

${ }^{10}$ Projeto Terapêutico é o “conjunto de atos assistenciais pensados para resolver determinado problema de saúde do usuário, com base em uma avaliação de risco. O risco não é apenas clínico, é importante enfatizar isto, ele é também social, econômico, ambiental e afetivo, ou seja, um olhar integral sobre o problema de saúde vai considerar todas estas variáveis na avaliação do risco. Com base no risco é definido o Projeto Terapêutico e a partir dele o trabalhador de saúde vai orientar o usuário a buscar na rede de serviços os recursos necessários ao atendimento à sua necessidade” (FRANCO; FRANCO, s/d).
}

Serv. Soc. \& Saúde, Campinas, SP v. 14, n. 1 (19), p. 39-56, jan./jun. 2015 ISSN 1676-6806 
gestor/diretor/coordenador), mas ao processo mesmo de pensar/decidir/executar/avaliar o trabalho, prerrogativa de qualquer trabalhador".

Tanto do ponto de vista individual quanto coletivo, a gestão do cuidado, nos remete à organização dos serviços e das práticas de saúde, tendo como eixo orientador a integralidade e as necessidades de saúde dos usuários. De acordo com Cecílio (2009 e 2011), a gestão do cuidado realiza-se pela articulação de múltiplas dimensões que se interpenetram e se condicionam mutuamente: individual, familiar, profissional, organizacional, sistêmica e societária.

No campo da saúde, o assistente social desenvolve um conjunto de ações que se integram no processo coletivo de trabalho, que abrange "ações ${ }^{11}$ de caráter emergencial, educação, informação e comunicação em saúde, planejamento e assessoria, mobilização e participação social" (COSTA, 2006, p.315). Tais ações podem abranger dimensões individuais, familiares e coletivas. Conforme revelou nossa pesquisa com assistentes sociais que trabalham na saúde, o cuidado aparece como constitutivo das ações profissionais do assistente social. Trata-se de um modo de olhar o usuário dos serviços numa perspectiva integral, do levantamento de recursos necessários para que o cuidado que necessita seja realizado, das informações prestadas quanto aos direitos, dos caminhos que o usuário pode percorrer para ampliar seu acesso aos serviços.

[...] ele perpassa por todas as ações profissionais, é a tua visão da integralidade da pessoa, acho que é a visão do profissional que está atuando [...]. S4;

[...] levantando quais são os recursos que ele tem para prestar determinados cuidados [...] acho que também é um cuidado mostrar para ele quais são esses direitos, quais são esses caminhos, trabalhar a questão da mobilização social, da mediação, da potencialização, para que eles possam estar indo atrás desse acesso, que muitas vezes é interrompido por várias questões [...] S1;

[...] Eu atuo no plantão social com pessoas com AIDS, com câncer [...] a questão do envolvimento da família nesse processo de tratamento, o cuidado com a família quando descobre o diagnóstico; então não fica só no sujeito, dependendo você vai para a família, se ele não tem família ele vai para uma instituição [...]. S4.

Do ponto de vista metodológico, o acolhimento, a escuta, o vínculo e a responsabilidade profissional, por exemplo, são atitudes ou posturas indispensáveis e

\footnotetext{
${ }^{11}$ As ações profissionais são compreendidas como "um conjunto de procedimentos, atos, atividades pertinentes a uma determinada profissão e realizadas por sujeitos/profissionais de forma responsável, consciente" (MIOTO, apud MIOTO et al., 2007, p. 112).
}

Serv. Soc. \& Saúde, Campinas, SP v.14, n.1(19), p. 39-56, jan./jun. 2015 ISSN 1676-6806 
constitutivas da concepção de cuidado em saúde e que estão presentes na Política de Assistência Social (SUAS) e na prática do assistente social desde sua origem.

Uma das estratégias para reorientar o modelo assistencial de saúde no país, a partir da atenção básica, é o Programa Saúde da Família (PSF), hoje denominado de Estratégia Saúde da Família, que aposta na criação de vínculos, na responsabilização e no compromisso dos profissionais de saúde com a população.

A discussão sobre o acolhimento não é "novidade" para a profissão. A pesquisa realizada por Chupel e Mioto sobre o acolhimento no serviço social, por exemplo, levantou a hipótese de que esta prática é "integrante do processo interventivo dos assistentes sociais e congrega três elementos que agem em concomitância: a escuta, a troca de informações e o conhecimento da situação em que se encontra o usuário" (CHUPEL; MIOTO, 2010, p. 55).

Nesse sentido, os sujeitos identificam que o acolhimento está presente em sua prática cotidiana desde o primeiro contato com o usuário e se constitui num momento em que o profissional, por meio da troca de informações, busca conhecer sua realidade social, suas demandas e necessidades de saúde em seu sentido ampliado.

Os depoimentos que se seguem mostram que o acolhimento é constitutivo da intervenção do assistente social e contribui para o planejamento e o estabelecimento de estratégias de ação. Tais ações são orientadas por sua visão "integral” do usuário sujeitos de direitos, pela postura ético-política e pelos objetivos profissionais.

[...] a gente faz esse acolhimento, a gente tem essa perspectiva desse sujeito de direitos, enquanto sujeito integral. Eu acho que o diferencial aí tem a ver com a postura ético-política do profissional, os objetivos profissionais que aquele profissional tem [...] S6.

[...] na AIDS, por exemplo, quando a gente atende, é você dar um atendimento digno, ouvir essa pessoa [...] eu tenho casos do limite entre a vida e a morte, gente que estava lá e voltou, está se tratando e está muito bem [...] isso para mim, que seja dez pessoas, já é significante e são pessoas que estão aqui e que dizem isto para mim [...]. S4.

[...] porque realmente você tem esse vínculo, na medida em que você estabelece, vai se constituindo esse relacionamento profissional de respeito, de ouvir a história, de valorizar, de junto com ele pensar algumas alternativas [...]. S4. 
O acolhimento, portanto, envolve uma escuta qualificada que transcende a coleta de informações; o ouvir ${ }^{12}$ se efetiva numa relação estabelecida com o usuário nos serviços de saúde com possibilidade de concretizar vínculos. Leloup refere-se ainda a um ângulo diferenciado ao cuidado quando se reporta ao estilo alexandrino de cuidar, ou seja, de se "fazer tudo que é necessário para cuidar da doença, evidentemente. Ao mesmo tempo, cuidar, igualmente, daquilo que está bem, do que não está doente no doente. Porque é a partir deste espaço de saúde que a cura poderá, talvez, ocorrer" (LELOUP, 2009, p. 36).

[...] então ele adoece menos porque ele acostuma buscar, ele está potencializado para isto a gente está dando essa autonomia, está junto construindo [...] S5.

Sabemos que, por meio da escuta, muitas intervenções nos serviços de saúde podem ser evitadas, pois as razões que levam um usuário a procurar atendimento médico, por exemplo, podem ocultar problemas que nem sempre são decorrentes de sofrimentos físicos, mas relacionados a outras dimensões da vida (econômicas, socioculturais, religiosas, familiares, afetivas, etc). Ao trabalhar outros aspectos da vida dos usuários o assistente social favorece também que outros atores profissionais cuidadores, "entrem em cena".

\section{O ASSISTENTE SOCIAL NO CUIDADO COM FAMÍLIAS E NA EQUIPE DE TRABALHO}

O cuidado em saúde não é exclusividade dos trabalhadores de saúde e nem se dá apenas na rede ${ }^{13}$ formal de serviços. Ela abrange múltiplas dimensões interligadas, entre as quais, a rede informal constituída pela família e dependendo da situação, pelos vizinhos e pela comunidade.

\footnotetext{
12 Madeira et al observam que “ ouvir o outro implica uma escuta para além da lógica tecnocientífica, com o reconhecimento da subjetividade dos sujeitos envolvidos no processo, possuidores de histórias e vivências singulares, onde os profissionais e usuários, ao se colocarem em uma atitude de escuta, se dispõem a se transformar e a transformar o outro" (MADEIRA ET AL (2007, p. 186).

13 Numa perspectiva macropolítica, o conceito de rede refere-se ao sistema de atenção à saúde como “[...] uma malha que interconecta e integra estabelecimentos e serviços de saúde de determinado território, organizando-os sistemicamente para que os diferentes níveis e densidades tecnológicas de atenção estejam articulados e adequados para o atendimento ao usuário e para a promoção da saúde” (SILVA; MAGALHÃES JÚNIOR, 2008, p.81). Do ponto de vista micropolítico, o conceito de rede baseia-se na ideia de que os trabalhadores de saúde "[...] através do trabalho vivo em ato, fazem rizoma, operando com base em fortes conexões entre si, onde a ação de alguns complementa a ação de outros e vice-versa. Há um dinâmico e rico cruzamento de saberes e fazeres, tecnologias, subjetividades, e é a partir desta configuração do trabalho, como um amálgama, que os atos de saúde se tornam produtivos e realizam o cuidado" (FRANCO, 2006).
}

Serv. Soc. \& Saúde, Campinas, SP v.14, n.1(19), p. 39-56, jan./jun. 2015 ISSN 1676-6806 
A introdução de programas como a desospitalização e atendimento domiciliar iniciada a partir da década de 1990, tem indicado uma crescente valorização da família no âmbito das políticas de saúde e assistência social ${ }^{14}$.

Mas, apesar do atual contexto de envelhecimento da população e da importância da família na produção do cuidado, o papel da família historicamente é pouco valorizado pela sociedade e pelos serviços de saúde, compreendido como se fosse algo natural, “já dado”. Minayo e Gutierrez ressaltam que apesar da importância da família na produção de cuidados especialmente na afetividade, na adesão aos tratamentos, na identificação das doenças e na procura por serviços médicos, seu reconhecimento é relativo. Para as autoras isso decorre como resultado

[...] do processo de colonização a que a área da saúde foi submetida pelo saber médico. Sob a égide do pensamento positivista, houve a redução da concepção de saúde à mera 'ausência de doença' e os cuidados assumiram a forma de 'ações e procedimentos técnicos' informados pela ciência biomédica e descolados do mundo vivido (MINAYO e GUTIERREZ, 2010, p. 1498).

Um dos aspectos frequentemente abordado por estudos sobre a família no processo de cuidar, diz respeito ao 'cuidador', suas dificuldades e seus conflitos que exige a atenção dos profissionais de saúde. Nesse sentido, ao estender o seu olhar para o contexto familiar dos pacientes, o assistente social pode identificar as possibilidades e as condições necessárias para que o cuidado seja realizado.

Os relatos a seguir mostram que os cuidadores não tinham condições de cuidar dos filhos, seja pela situação inusitada e complexa das doenças ou por negligência, pois eles também precisavam ser cuidados.

[...] eu atuo com as famílias de crianças e adolescentes com HIV e daí envolve o cuidado aqueles que são responsáveis e muitas vezes descuidam, e aí vem os nossos valores [...] uma vez eu fui muito dura com uma mãe que não estava dando a medicação para a criança; ela não vinha buscar a medicação e os exames mostraram que a criança não estava recebendo a medicação [...] eu fui muito firme com ela que começou a chorar: 'não adianta chorar, vc tem que cuidar, isto é uma obrigação de mãe' [...] S5

Ao mesmo tempo, essa perspectiva de trabalho do assistente social revela que sua atuação é permeada por conflitos interpessoais relativos aos valores e preconceitos que emergem das relações com os usuários. A relação entre o profissional e o usuário, na perspectiva da alteridade, do respeito à diversidade cultural e familiar, produz diferentes reflexões e questionamentos para o próprio profissional.

\footnotetext{
${ }^{14}$ Estratégia Saúde da Família, Bolsa família, Proteção e Atendimento Integral à Família (PAIF) e outros.
} 
[...] será que ela tem isso para dar e qual a visão que ela tem de ser mãe e de cuidar, então eu fui repensar os meus valores, a minha exigência, e aí perceber que ela tem que ser cuidada pelo serviço e pela equipe para poder saber cuidar dessa criança, porque não é automático: - a mãe cuida, a mãe ama; [...] foi uma experiência muito difícil, embora tenha surtido um resultado bom [...] já não sei se foi a bronca, a firmeza, ou se foi um repensar que mudou minha relação com ela; eu sei que hoje ela dá a medicação correta, não deixa mais de vir, mudou muita coisa [...]. S5.

Os exemplos mencionados mostram que este trabalho exige um profissional que se coloque por inteiro na busca de alternativas para os problemas que enfrenta, renegociando suas ações consigo mesmo, com os usuários e com os demais trabalhadores. Nesse sentido, ao analisar o contexto familiar e identificar necessidades dos usuários que exigem um atendimento diferenciado ou que foge das regras estabelecidas, a negociação com a equipe de trabalhadores nas unidades de saúde também se faz necessária. $\mathrm{O}$ cuidado abrange o contexto organizacional da política de saúde e dos conceitos correlatos que o campo possa exigir.

[...] nós tivemos um caso recentemente, a gente fez a equipe perceber, porque a princípio foi resistente, porque exigia coisas que nem a equipe dá conta, uma das falas foi assim: porque que a gente vai tratar ela diferente dos outros? É que no momento, no contexto familiar dela, necessitava desse atendimento diferenciado dos outros, para que a gente pudesse estar trazendo ele e vinculando ao nosso serviço. Então, quando a gente, o Serviço Social pode demonstrar isso para os outros profissionais e articular isso, eu acho que foi articulação de cuidado. S1;

[...] na questão da adesão ao tratamento do doente crônico, com AIDS, com transtorno mental, várias patologias [...] se a equipe não tiver essa visão do cuidado como um todo é muito difícil esse paciente aderir, porque a adesão envolve: o sujeito, o profissional, o serviço de saúde, a família, então, é todo o contexto que ele vive [...] se não tiver esse olhar ela cai por terra. S4.

Do ponto de vista da gestão do cuidado, portanto, o trabalho em equipe e a atenção aos princípios da universalidade e da equidade são imprescindíveis, além da integração de diferentes olhares e objetivos profissionais, abertura para o outro, postura de cooperação, de articulação de processos de trabalho e do reconhecimento da contribuição de diferentes saberes. 


\section{A (IN)VISIBILIDADE DO CUIDADO E A DIFICULDADE EM IDENTIFICAR SEUS RESULTADOS}

$\mathrm{Na}$ pesquisa que realizamos observamos que as assistentes sociais têm dificuldades para indicar os componentes que poderiam mensurar o "resultado" do trabalho que realizam no campo do cuidado, quando suas ações são comparadas com as ações dos demais profissionais de saúde. Apesar de reconhecerem que estão "produzindo cuidado" quando acolhem o usuário e procuram compreender o seu contexto e as necessidades trazidas, mas não conseguem atribuir visibilidade ao trabalho que realizam.

[...] se eu sou enfermeira e eu dei conta daquela ferida eu cuidei daquele paciente; se eu sou médico e faço o diagnóstico eu cuidei do paciente; [...] eu acho que a todo momento você produz esse cuidado, mas nem sempre vai ver resultados concretos de benefícios. S3

Percebemos, então, que a produção do cuidado é sempre relacional e acontece no encontro entre os sujeitos; mas, identificar seus resultados no sistema produtivo requer perceber o processo de evolução do serviço. Como propõe Merhy e Franco (s/d), é preciso um "olhar" dirigido à micropolítica dos processos de trabalho e, nesse sentido, quando compreendemos que a produção na saúde diferencia-se da produção industrial e, portanto, requer outros indicadores para avaliar os processos de trabalho e seus resultados ou produtos.

A produtividade na saúde é uma questão complexa quando se pensa em estabelecer medidas e depende do significado atribuído ao termo "produto". Nessa direção, não se pode medir a produtividade apenas considerando a realização de procedimentos médico-hospitalares tais como: consulta médica, vacinas, curativos, exames, tratamento de cáries dentárias, etc. Como serviço oferecido à população, devese incluir no critério de produtividade as interações entre os profissionais de saúde e os usuários como, por exemplo: o acolhimento, a escuta qualificada, a preocupação com as suas necessidades.

[...] eu estava lembrando de um paciente que tem esquizofrenia, que em poucos atendimentos, de conversar, de descobrir o que ele gosta de fazer [...] a mãe também estimulando e tal, com a medicação correta [...] hoje ele está saindo com os amigos, participando de exposição de artes, fazendo coisas, a mãe veio contar [...] nossa, será que foi a partir de algumas conversas, de alguns atendimentos, até a gente ficou [...] são sementinhas sim, são coisas pequenas que a gente vai plantando, mas às vezes a gente não vê, não presencia a mudança na dimensão que ela realmente tem na vida daquela pessoa [...]. S1. 
Aliás, a dimensão micropolítica do trabalho do assistente social não é bem percebida ou relacionada às mudanças "concretas" nas condições de vida do usuário, especialmente, se a expectativa do profissional estiver relacionada apenas às transformações macro políticas ou diretamente condicionada às mudanças socioeconômicas.

[...] eu acho que no cotidiano da pessoa essa diferença que pode fazer a intervenção do assistente social como cuidador de saúde, não sei, eu acho que no concreto, no dia a dia, é muito lento, não existe uma mudança significativa na vida daquela pessoa, pode ter algumas mudanças [...] mudança para mim é melhorar suas condições concretas de vida, melhorar as coisas a partir daí [...] o BPC pode melhorar as condições concretas da vida de uma pessoa ou ele pode piorar, dependendo da perspectiva [...] se é um usuário (de drogas) o BPC foi pro saco ali no consumo [...] então, até que ponto, que mudança foi essa [...] S7.

[...] o que você aceita como mudança se for uma mudança grande, visível, mais externa, eu acho que depende muito do que você entende por mudança [...] se eu ficar achando que vai ser uma mudança grande, aí eu vou considerar [...] mas, de repente uma palavra, um atendimento pode gerar uma mudança que pode motivar alguma coisa muito positiva, pode desvendar alguma coisa que ela mesmo tem, (despertar para outras coisas) desmistificar, alguma coisa assim [...] então, eu acho que a gente faz, não é que a gente faz mais, eu acho que a gente possibilita mais para eles [...]. S1.

Isto reforça a importância de ressignificar a dimensão micro buscando, conforme observam Pinheiro et al, superar dicotomias e dualismos existentes, entre

[...] indivíduo-sociedade, teoria-prática, Estado-sociedade, macromicro [...] entendida não como um pólo ou extremo, mas um espaço de relações e interações, um território de flexibilidade e segmentaridade com as dimensões macro e molecular, cujas características encontram afinidades com o conceito de molar proposto por Deleuze e Guattari (1996). (PINHEIRO et al, 2005, p. 42).

Talvez mais do que ressignificar é importante compreender a intrínseca relação entre a atuação micro e macro social. E, neste sentido, o conceito formulado por Rodrigues nos auxilia a alcançar maior compreensão.

Priorizar nas práticas do assistente social a perspectiva da 'microatuação' significa a tentativa de ultrapassar concepções equivocadas, antagônicas ao político, ao global. Por perspectiva 'micro' entenda-se o espaço plural de ações e gestões localizadas, pontuais e diversificadas que constituem o cotidiano do exercício profissional (RODRIGUES, 1998, p. 91). 
Para Rodrigues, a compreensão de contextos “micro" precisa ser articulada às análises macroexplicativas e conjunturais da realidade sem, contudo, polarizar as distintas dimensões. A autora ressalta ainda que, a apreensão das peculiaridades no plano "micro" consiste num movimento que articula todo e parte, e isto exige que o assistente social realize mediações, adquira habilidades, conhecimentos e instrumentos que contribuam para responder às demandas em diferentes contextos de seu trabalho.

A partir desta compreensão o profissional de saúde potencializa as mudanças que se processam na dimensão micropolítica da vida dos usuários e do contexto institucional, ou seja, compreende que as alterações se processam nas relações sociais cotidianas compreendendo-as como um espaço de transformação social nas dimensões singular e particular, humana e genérica.

\section{CONSIDERAÇÕES FINAIS}

Dado o caráter multidimensional e polissêmico do cuidado na área da saúde recorremos a uma abordagem multirreferencial como ferramenta analítica para focalizálo em seus aspectos macro e micropolíticos, compreendendo que essas dimensões estão em permanente intercâmbio. Entendemos que, numa perspectiva macropolítica, a política de humanização, de educação permanente em saúde, e o próprio SUS, são dispositivos e estratégias que buscam, apesar das contradições existentes, resgatar a dimensão cuidadora nos profissionais de saúde.

Por outro lado, a operacionalização e efetivação, dessa política dependem do trabalhador em sua micropolítica nas "estações" em que atua (unidades de saúde, domicílio e/ou outros), vinculada a atitude do profissional, às suas concepções sobre o processo saúde-doença, das representações e percepções do outro e de si mesmo que podem conduzir a um modo de ser mais ou menos cuidador.

As concepções de cuidado em saúde para as assistentes sociais emergem associadas ao projeto ético-político do Serviço Social no que tange ao compromisso, respeito aos usuários, escuta como valores constitutivos da ação profissional e, isto, no nosso entendimento, dialoga intensamente com o enfoque teórico aqui adotado. Além das variadas concepções sobre o cuidado em saúde que emergiram nos grupos e que se 
complementam, as formas de realizá-lo se mostraram diferenciadas e vinculadas às percepções e experiências individuais dos sujeitos em seus espaços de trabalho.

Embora a formação do assistente social faça pouca ou nenhuma menção a esta perspectiva de ação, relacionando-a mais a uma atitude do que um dispositivo importante na relação de trabalho, ela está subjetivamente presente na prática profissional.

Assim, a discussão sobre o 'cuidado na área da saúde' pode ser considerada como temática analítica permitindo contextualizar a atuação do assistente social numa dimensão macro e micropolítica, ressignificando a prática profissional através de conhecimentos que substanciem melhor o cotidiano de trabalho. Tratar do cuidado em saúde como uma questão teórica e técnica, certamente, contribuirá para a maturação e maior qualificação dos conhecimentos nesta área e no âmbito do Serviço Social.

Recebido em 28.04.2015 - Aprovado em 19.06.2015

\section{REFERÊNCIAS}

BARROS, M. E. B.; BARROS, R. B. A potência formativa do trabalho em equipe no campo da saúde. In: PINHEIRO, R.; MATTOS, R. A.; BARROS, M. E. B. (Org.). Trabalho em equipe sob o eixo da integralidade: valores, saberes e práticas. Rio de Janeiro: IMS/UERJ: CEPESC: ABRASCO, 2007. p.75-84.

BRASIL. Ministério da Saúde. Lei 8.080, de 19 de setembro de 1990. Lei Orgânica da Saúde. Dispõe sobre as condições para a promoção, proteção e recuperação da saúde, a organização e o funcionamento dos serviços correspondentes e dá outras providências. Disponível em:<http://portal.saude.gov.br/portal/arquivos/pdf/ lei8080.pdf>. Acesso em: 30 ago. 2013.

CASTRO E CASTRO, M. M. Serviço Social e cuidado em saúde: uma articulação necessária. Libertas, Juiz de Fora, v.6, 7, n.1, 2, p. 128-148, jan-dez., 2007. Disponível em:<http://www.editoraufjf.com.br/revista/index.php/libertas/article/ view/1769/0>. Acesso em: 5 maio 2013.

CECÍLIO, L. C. O. As necessidades de saúde como conceito estruturante na luta pela integralidade e equidade na atenção em saúde. In: PINHEIRO, R.; MATTOS, R. A. de (Org.). Os sentidos da integralidade na atenção e no cuidado em saúde. Rio de Janeiro: UERJ, IMS: ABRASCO, 2001. p.113-126. 
CECÍLIO, L. C. O. A morte de Ivan Ilitch, de Leon Tolstói: elementos para se pensar as múltiplas dimensões da gestão do cuidado. Interface: Comunic. Saúde, Educ, Botucatu, v.13, supl.1, p. 545-55, 2009.

CECÍlLIO, L. C. O. Apontamentos teórico-conceituais sobre processos avaliativos considerando as múltiplas dimensões da gestão do cuidado em saúde. Interface, Comunic. Saúde, Educ, Botucatu, v.15, n.37, p. 589-599, 2011. Disponível em: $<$ http://www.scielo.br/scielo.php?pid=S141432832011000200021\& script= sci_arttext>. Acesso em: 29 abr. 2013.

CHUPEL, C. P.; MIOTO, R. C. T. Acolhimento e Serviço Social: contribuição para a discussão das ações profissionais no campo da saúde. Serviço Social \& Saúde, Campinas, v. 9, n. 10, p. 37-59, 2010.

COSTA, M. D. H. O trabalho nos serviços de saúde e a inserção dos(as) assistentes sociais. In: MOTA, A. E. et al. (Org.). Serviço Social e Saúde: Formação e trabalho profissional. São Paulo: OPAS, OMS, 2006. Cap. 7, p. 304-351.

DESLANDES, S. F. O cuidado humanizado como valor e ethos da prática em saúde. In: PINHEIRO, R.; MATTOS, R. A. (Org.). Razões públicas para a integralidade em saúde: o cuidado como valor. Rio de Janeiro: IMS/UERJ, CEPESC: ABRASCO, 2007. p.385-395.

FRANCO, T. B. As Redes na Micropolítica do Processo de Trabalho em Saúde. In: PINHEIRO, R.; MATOS, R.A. Gestão em Redes. Rio de Janeiro: LAPPIS-IMS/UERJABRASCO, 2006. p.459-473.

FRANCO, C. M.; FRANCO, T. B. Linhas do Cuidado Integral: uma proposta de organização da rede de saúde. Porto Alegre: Secretaria de Estado de Saúde do RS. Disponível em:<http://www.saude.rs.gov.br/dados/1306960390341linha-cuidadointegral-conceito-como-fazer.pdf>. Acesso em: 9 nov. 2012.

LACERDA, A.; VALLA, V. V. As práticas terapêuticas de cuidado integral à saúde como proposta para aliviar o sofrimento. In: PINHEIRO, R.; MATTOS, R. A. (Org.).

Cuidado: as fronteiras da integralidade. Rio de Janeiro: CEPESC/UERJ, ABRASCO, 2005. p.91-102.

LELOUP, J. Y. Uma arte de cuidar: estilo alexandrino. Petrópolis: Vozes, 2009.

MADEIRA, L. M. et al. Escuta com cuidado: é possível ensinar? In: PINHEIRO, R.; MATTS, R. A. (Org.). Razões públicas para a integralidade: o cuidado como valor. Rio de Janeiro: CEPESC/UERJ, ABRASCO, 2007, p. 249-262. 
MERHY, E. E. Saúde: a cartografia do trabalho vivo. São Paulo: Hucitec, 2002. (Saúde em Debate).

MERHY, E. E.; FRANCO, T. B. Reestruturação produtiva e transição tecnológica na saúde $(\mathrm{s} / \mathrm{d})$.

Disponível

em:

http://www.professores.uff.br/tuliofranco/textos/reestruturacao_produtiva_e_transicao_t ecnologica_na_saude_emerson_merhy_tulio_franco.pdf Acesso em: 16 março 2015.

MINAYO, M. C. S.; GUTIERREZ, D. M. D. Produção de conhecimento sobre cuidados da saúde no âmbito da família. Ciência \& Saúde Coletiva. Rio de Janeiro, v.15, supl.1, Jun, 2010. Disponível em:<http://www.scielo.br/scielo.php? pid=S1413-81232010000700062\&script=sci_arttext $>$. Acesso em:14 out. 2012. MIOTO, R. C. T.; ROSA, F. N. Processo de construção do espaço profissional do assistente social em contexto multiprofissional: um estudo sobre o Serviço Social na Estratégia Saúde da Família. Relatório. Florianópolis: UFSC, Centro Sócio Econômico Departamento de Serviço Social, 2007. mimeo

PINHEIROS, R. et al. Matriz analítica de experiências de ensino para integralidade: uma proposição observacional. In: PINHEIROS, R.; CECCIM, R. B.; MATTOS, R. A. DE. (Org.). Ensinar saúde: a integralidade e o SUS nos cursos de graduação na área da saúde. Rio de Janeiro: IMS/UERJ, CEPESQ, ABRASCO, 2005. p.37-54. RODRIGUES, M. L. Prática profissional: reinventado o espaço da microatuação. In: Serviço Social \& Realidade - 20 Anos, No. 06, Unesp/Franca, São Paulo,1998. SILVA, A. M. M. F. Produção do cuidado em saúde e o Serviço Social. São Paulo, 2013. 251p. Tese (Doutorado em Serviço Social). Pontifícia Universidade Católica de São Paulo. 2013. SILVA, S. F.; MAGALHÃES JUNIOR, H. M. Redes de atenção à saúde: importância e conceitos. In: SILVA, S. F.. (Org.). Redes de atenção à saúde: o pacto pela saúde e redes regionalizadas de ações e serviços de saúde. Campinas: IDISA: CONASEMS, 2008. p. 69-85. 
Serv. Soc. \& Saúde, Campinas, SP v. 14, n. 1 (19), p. 39-56, jan./jun. 2015 ISSN 1676-6806 